\title{
EFÍMEROS. \\ LA DICHA DEL SER HUMANO EN PÍNDARO \\ Y PLATÓN
}

\author{
ALFONSO FLÓREZ \\ Pontificia Universidad Javeriana (Bogotá)
}

\begin{abstract}
RESUMEN: A partir de una lectura conjunta de la Pítica 8 de Píndaro y el libro 10 de la República de Platón, se estudian las relaciones que en la vida humana guarda lo efímero con la dicha. El poema pindárico ofrece determinaciones decisivas para la comprensión de lo efímero en el ser humano, en el sentido de que en medio de la precariedad la dicha aún puede alcanzar al ser humano. Hay razones para pensar que el texto platónico trabaja sobre el texto pindárico, lo que ofrece elementos nuevos para la interpretación del mito de Er como gesto poético supremo de Platón, lo que permitirá plantear una nueva comprensión de las relaciones entre filosofía y poesía.
\end{abstract}

PALABRAS CLAVE: Platón; Píndaro; filosofía y poesía; filosofía griega; lírica griega antigua; inmortalidad del alma.

\section{Ephemerals \\ The Bliss of the Human Being in Pindar and Plato}

ABSTRACT: A joint reading of Pindar's Pythian 8 and Plato's Republic 10 is carried out with the purpose of examining the relationships between the ephemeral and the bliss in a human life. The Pindaric poem offers decisive suggestions in order to understand the place of the ephemeral in the human being since it is shown that in middle of precariousness the bliss still can reach the human being. There are reasons to think that the Platonic text follows in some relevant features the Pindaric text. This provides new elements that allow the interpretation of the Myth of Er as the supreme Plato's poetic gesture. Consequently, a new way of comprehending the relationships between philosophy and poetry can be stated.

KEY WORDS: Plato; Pindar; philosophy and poetry; Greek philosophy; Greek ancient lyric; human soul immortality.

\section{INTRODUCCIÓN}

Reconociendo, por un lado, que para el pensamiento de Platón es esencial tomar posición frente a la poesía - posición que por lo general se entiende como de censura y rechazo, aunque no siempre ${ }^{1}$, pero constituyendo Píndaro, por otro lado, uno de los autores más connotados de la Antigüedad ${ }^{2}$ y siendo él mismo uno de los poetas que recibe un mayor número de citas y referencias en la obra de Platón ${ }^{3}$, no deja de

1 Cf. Elias (1984), Fendt y Rozema (1998) y, más recientemente, con sutileza e ingenio extraordinarios, PradeAu (2009).

2 Era ya la opinión de Quintiliano; cf. Race (2012), 1.

3 Mitscherling (2009) da las siguientes cifras del conjunto de citas y referencias, tanto a obras como personales: (1) Homero: 203; (2) Hesíodo: 49; (3) Eurípides: 24; (4) Solón: 24; (5) Píndaro: 23; (6) Orfeo: 22; (7) Esquilo: 14; (8) Simónides: 13; (9) Sófocles: 9; (10) Tirteo: 
extrañar la poca atención que se ha dedicado a la relación entre los dos grandes autores ${ }^{4}$.

Estos estudios, en efecto, cuando no han sido de carácter general -mostrando las afinidades en la perspectiva adoptada por los dos autores ${ }^{5}$-, se han centrado casi exclusivamente en aspectos filológicos, interesantes, sí, pero muy particulares ${ }^{6}$. A este respecto, el libro 10 de la República ofrece una amplia oportunidad de reflexión, pues allí no sólo se aborda la cuestión de la relación entre filosofía y poesía, sino que se tratan los temas de la inmortalidad del alma y de su destino escatológico — de la mano del mito de Er-, motivos todos donde el estudioso no dejará de encontrar ocasión para un fructífero encuentro con Píndaro, en particular con la Pítica $8^{7}$.

Dentro de este contexto, un estudio reciente ha dado un paso más allá al proponer un vínculo específico entre los dos textos ${ }^{8}$. Haciendo pie en esta esclarecedora idea, el presente trabajo se propone la elaboración de un conjunto más amplio de relaciones entre los dos textos, de forma tal que cada uno de ellos resulte enriquecido con la lectura del otro.

\section{Efímeros en la Pítica 8 de Píndaro}

Expertos comentaristas no han dudado en llamar la Pítica 8 «el mayor poema de Píndaro que nos ha llegado ${ }^{9}$, observación que no sólo debe servir

7. Si las cifras se limitan a citas directas, la situación sufre un cambio apreciable, así: (1) Homero: 117; (2) Hesíodo: 14; (3) Píndaro: 10; (4) Eurípides: 8; (5) Esquilo (8); (6) Simónides: 6; (7) Sófocles: 4; (8) Solón: 3; (9) Orfeo: 3; (10) Teognis: 3. Mitscherling ofrece los lugares de la obra platónica donde se dan estas citas y referencias, 323-343. MilLER (2002) da cifras ligeramente diferentes, pero también significativas en relación con Píndaro.

4 Ello a pesar de las protestas de Jaeger, que se lamentaba de que «en las introducciones a nuestras ediciones de Platón no se dice una palabra de Píndaro», JAEGER (2001), 207; en su amplio estudio, no de detalle, él mismo destaca la comunidad aristocrática entre los dos autores, que los lleva a gravitar alrededor del ejemplo ilustre como paradigma de formación. De los estudios recientes sobre Platón, MiLler (2011) le asigna una presencia importante a Píndaro. Asimismo, von der WALDE (2010) ofrece una interesante propuesta interpretativa donde identifica a Píndaro con el poeta de República 2; FlóREz (2016) presenta una elaboración ulterior de la reflexión de von der Walde.

5 Places (1947). Mención especial merece FränKel (1993), que tiene un juicio claro sobre la cercanía espiritual entre los dos autores.

6 Cf. Miller (2002) y su iluminador estudio de la cita pindárica de Gorgias, 484b.

7 Para la relación entre filosofía y poesía en Platón y Píndaro, cf. ADAM (2009), II, 417, nota a República, 607b. Para la inmortalidad del alma en Píndaro, cf. Roнde (1994), 215-219. Para Píndaro como fuente del mito de Er, cf. Calabi (2007), 289. Notopoulos (1944) y Miller (2011) representan aportes más sustantivos, si bien ninguno trata específicamente el mito de Er en relación con Píndaro.

8 Cf. SiLK (2001). En concreto, Silk vincula la Pítica 8, 76-100 con la República 10, 617de, y si bien su consumado arte filológico lo ayuda a identificar pasajes convergentes en ambos textos, la premura del análisis y cierta predisposición hacia el filósofo lo llevan a confirmar el dogmatismo doctrinal de Platón frente a la apertura interpretativa de Píndaro.

9 CARNE-Ross (1985), 189; xviii: «his eighth Pythian, last and greatest of the many poems he wrote for Aigina». 
como advertencia para las limitaciones de quien no siendo filólogo se aventure en las tormentosas aguas de su interpretación - aunque en el presente caso se tomarán las debidas salvaguardas para no someter al lector a fantasiosas o, peor, falaces lecciones ${ }^{10}$ —, sino que sobre todo debe orientar en el sentido de que aquí se articula una relación prodigiosa entre dos autores magistrales.

En relación con Píndaro - y como mera instancia ilustrativa-, hay que decir que su obra conservada consiste principalmente en cantos de elogio - conocidos como epinicios - dirigidos a vencedores en cada uno de los sagrados cuatro grandes juegos panhelénicos, en Olimpia, Delfos, Corinto y Nemea, de donde toman los nombres de Odas Olímpicas, Píticas —por la Pitia, la vidente y sacerdotisa del templo de Apolo en Delfos-, Ístmicas - evidentemente por el istmo de Corinto-y Nemeas.

En este caso, al tratarse de un canto de elogio asociado a una ocasión determinada, el epinicio debe contener los nombres del atleta vencedor, de su padre y de su ciudad, ha de identificar la prueba y los juegos en que se dio la victoria, y también hacer una alusión al autor que con estos versos lleva a la inmortalidad la fama del atleta ${ }^{11}$. Salvo este último aspecto, los demás elementos se proclaman públicamente por el heraldo de los juegos y se encuentran en las listas oficiales y en diversas inscripciones.

El canto del poeta se contrata por la familia del vencedor o por él mismo y se ejecuta en su ciudad de origen varias semanas después de la prueba, dando tiempo así a la preparación de los coros y de las danzas, quizás en ocasiones bajo la dirección del propio poeta. El arte del poeta se muestra en la incorporación de estos elementos en un canto de elogio en el que se entremezclan argumentos atléticos y sentencias morales, con referencias a la familia y a la historia de la ciudad, siempre con mención de la divinidad y con frecuencia con recurso al mito como instancia paradigmática que sirve para asociar los triunfos actuales con gestas legendarias en las que toda la comunidad se reconoce.

Esto no quiere decir, empero, que el epinicio tenga una estructura establecida o una longitud determinada, aspectos variables que han suscitado y siguen suscitando acaloradas controversias respecto de «la unidad del epinicio»" si bien las referencias míticas adoptan con frecuencia una organización en quiasmo o anular (ring-composition), propia de la épica, donde el desarrollo de los elementos se da en orden inverso al de su primera mención. Es

10 En el orden filológico, aquí se recurre a la guía de los siguientes textos: BuRnETT (2005), Carne-Ross (1985), Gildersleeve (1885), Lefkowitz (1977), Nagy (1990; 2000), Pfeijffer (1995; 1999), Robbins (1997), SEgal (1998), Theunissen (2008). Por razones intrínsecas al argumento, la línea filosófica que se adopta se aviene mejor con las lecturas de Carne-Ross, de Nagy y de Theunissen, sin serles servil.

11 Cf. Sigelman (2016) para el estudio de la inmortalidad poética en Píndaro, esto es, la que se configura a partir de las propias estructuras formales del poema, necesaria, por ende, a diferencia de cualquier pretendida inmortalidad histórica o bibliográfica, meramente contingente al poema como tal. Este enfoque en relación con Píndaro y con Platón, si bien a partir de la Olímpica 2 y del Gorgias, se desarrollará en un trabajo posterior.

12 Cf. SILK (2012). 
característico de la composición pindárica el uso de fórmulas de interrupción en la consideración de un tema determinado (Abbruchsformeln; recusationes), lo que dota al conjunto de un sentido de espontaneidad que lo acerca a las expectativas propias del lector.

\subsection{Estructura y motivos}

La Pítica 8, con la certeza propia de estos asuntos ${ }^{13}$, se ha datado en el año 446 a.C., y sería así la última composición del poeta, ya entonces arriba de los setenta años. En ella se canta a un joven vencedor en la lucha, Aristómenes, procedente de la isla de Egina, con lo que esta oda se inscribe dentro del catálogo de once odas eginetas, que junto con las quince sicilianas constituyen más de la mitad de los epinicios ${ }^{14}$.

Hay que recordar que originariamente Egina, hija del dios-río Asopo, es amada por Zeus y llevada a la isla de Enone, que en lo sucesivo cambiará su nombre por el de la joven. De esta unión proviene Éaco, lo que da ocasión al poeta para asociar el nombre de Egina con el de los descendientes de Éaco, los Eácidas, entre los que se cuentan nada menos que Aquiles y Ayante, hijos de dos hijos de Éaco, Peleo y Telamón, respectivamente ${ }^{15}$. El canto se compone de cien versos, que pueden agruparse en cinco unidades de veinte versos, cada una de ellas dividida a su vez en tres secciones, una estrofa de siete versos, una antístrofa de siete versos y un epodo de seis versos. Se piensa que con esta organización se marcaban la dirección y el tiempo del coro y de la danza, conformes, por supuesto, con la composición anular, pero desde la época helenística se suprimió en la transmisión la música y las instrucciones corales de los epinicios pindáricos.

A riesgo de simplificar, puede decirse que con la primera tríada la acción poética se sitúa en el ámbito primigenio del orden cósmico universal, que prevalece así tenga que enfrentar a los enemigos más poderosos ${ }^{16}$. Con la segunda tríada la acción se vuelve hacia Egina y al lustre de la isla y de la familia del vencedor. En la tercera tríada se desarrolla el motivo mitológico de la expedición de los Epígonos que, a diferencia de sus padres, los Siete contra Tebas, habrían de alcanzar la conquista de la ciudad. De este modo, en la cuarta tríada, en medio de invocaciones a la divinidad, se exponen los triunfos

13 Cf. PfeiJfFer (1999), 425, donde la referencia del escoliasta a los XXXV Juegos Píticos, agosto de 446 a.C., se refuerza con consideraciones de índole histórica sobre las tensas relaciones políticas entre Atenas y Egina: «Thus P.8 is the latest Pindaric ode which can be dated with any certainty».

14 Cf. Morrison (2011). Grimal.

15 Cf. Grimal (1981), 152, 406. Las explicaciones mitológicas subsiguientes se basan en

16 PfeijfFer (1995) lee la primera tríada desde una perspectiva histórica que, sin duda, no agota toda su carga de sentido. 
del joven atleta. Por último, en la quinta tríada la reflexión se eleva a un plano universal, advirtiendo que el ser humano puede tanto del dios recibir la gloria, como padecer una caída intempestiva ${ }^{17}$.

Queda clara la estructura anular de la oda, en la cual la primera y la quinta tríada se corresponden en el sentido de que el discurso se desarrolla en un nivel universal y casi impersonal que, sin embargo, alberga en sí los referentes de la acción particular que da ocasión al canto. La segunda y la cuarta tríadas se corresponden en cuanto hacen la presentación y el elogio del vencedor, de su familia y de su patria. La tercera tríada se aloja en el centro de la composición, dando a entender que en el motivo mitológico se halla la justificación última tanto de la victoria que se canta como de la loa del poeta. A continuación se desarrollarán estos motivos dentro del propósito de allegar elementos que, en su relación con el texto de Platón, contribuyan a la mutua comprensión de los dos autores.

\subsection{Subida y caída}

«Amistosa Calma, hija de Justicia!» (1) ${ }^{18}$.

La primera tríada se abre con una invocación a Tranquilidad — Hesiquia-, hija de Justicia —Dike-, ella misma una de las Horas, junto con Disciplina -Eunomía - y Paz -Eirene-, hijas las tres de la unión de Zeus con Temis, «las cuales protegen los trabajos de los hombres mortales» ${ }^{19}$. Es difícil no ver, pues, en esta referencia a Tranquilidad la connotación de una situación primigenia de calma, orden y armonía que deriva de la justicia. Es importante hacer notar que ya desde el primer verso la oda pindárica desarrolla el motivo fundamental de la sucesión de las generaciones ya que la obra de Tranquilidad deriva de Justicia.

17 Así expone GildersLeEve (1885), 327, el conjunto de la oda: «To sum up: The first triad is occupied with the praise of Hesychia, ending in praise of the victor. The second triad begins with the praise of Aigina, and ends with the Midylidai, to whom the victor belongs. The third triad gives the story of Alkmaion, as an illustration of the persistency of noble blood. The fourth acknowledges the goodness of Apollo, and entreats his further guidance; for God is the sole source of these victories, which are now recounted. The fifth presents a striking contrast between vanquished and victor, and closes with an equally striking contrast between the nothingness of man and the power of God, which can make even the shadow of a dream to be full of light and glory. At the end is heard a fervent prayer, for Aigina's welfare». BuRNETT (2005), 227, es más sintética: «A system of five triads produces a cleanly marked sequence of invocation, turn towards Aigina and victor, mimesis of mythic episode, prayerful precaution, and direct praise».

18 PínDARo se cita según la traducción de Suárez de la Torre (2000), aunque, teniendo a la vista el texto bilingüe griego-inglés de Race (2012a), se han introducido algunas variaciones menores en la versión final.

19 Hesíodo, Teogonía, 901-903. 
«Tú, que das grandeza a las ciudades!»(2).

Sólo en un segundo momento se le asigna a Tranquilidad una función política, quizás como desarrollo de la línea hesiódica de que las Horas protegen los trabajos de los mortales.

«¡Tú, que de las decisiones y de las guerras

posees las llaves supremas!» (3-4).

Sin embargo, la tarea de Tranquilidad no debe confundirse con pusilanimidad; esta divinidad obra en las asambleas, donde se toman las decisiones de ir a la guerra, tal vez con el sentido de que en ocasiones hay que entrar en combate si se quiere preservar la armonía y la concordia.

«¡Acepta este honor por la victoria pítica de Aristómenes!» (5).

El honor es la invocación y el canto que el poeta le ofrece a Tranquilidad, hija de Justicia, fortaleza de ciudades, y ella misma defensora de la guerra, si es necesario. La victoria de Aristómenes en los Juegos Píticos se le dedica a la diosa, con lo que ya desde el mismo ofrecimiento la victoria dice tanto de la grandeza de la ciudad exaltada, como del riesgo involucrado en ello. Hay que hacer notar que ya desde este momento, en el ofrecimiento a la divinidad, se entrecruzan los dos motivos de la victoria del atleta y del canto del poeta.

«Tú sabes por igual, es cierto, conceder y recibir gratos dones

con la oportunidad precisa» (6-7).

La divinidad concede (érxai) gratos dones (tò malthakón) y asimismo los recibe (te kaì patheîn) como corresponde a su condición: en la oportunidad precisa (kairôi sùn atrekê̂). Es decir, la victoria de Aristómenes que junto con la oda que la canta se le ofrece ahora a la diosa corresponde a una primera dádiva divina y el ofrecimiento humano no puede sino esperar coincidir con la ocasión propicia determinada por la divinidad.

En los demás versos de esta primera tríada se expone cómo Tranquilidad, cuando recibió las provocaciones llenas de insolencia (húbrin, 12) de Porfirión, rey de los Gigantes, y de Tifón, los abatió por medio del rayo y de las flechas de Apolo, dios este último que ahora en el Parnaso concede la fama al hijo de Jenarces. De este modo la hazaña del atleta se vincula a las gestas primordiales de los dioses cuando en combate tuvieron que imponer el orden olímpico frente a violentas divinidades ctónicas. Hay que hacer notar que, tanto en el ámbito divino como en el humano, la gloria se alcanza en la asociación de las generaciones, allí, Tranquilidad con Apolo y Zeus, cuyo nombre piadosamente se calla, aquí, Aristómenes y Jenarces, su padre; incluso la insurrección de los dioses entre Porfirión y los Gigantes y Tifón responde a este motivo genealógico.

Es también pertinente recalcar que los movimientos que aquí se describen se realizan en el plano vertical: "arrojar a la sentina la desmesura», es decir, «echarla a pique» (tithê̂s húbrin en ántloi, 11-12), "la violencia también al 
orgulloso derriba (ésphalen) a su tiempo» (15), «domeñados (dmâthen) fueron por el rayo» (17). Así el poeta vincula el tema del deporte de la lucha con sus levantadas y caídas a los movimientos de exaltación y de hundimiento suscitados por la divinidad, asociación que encontrará su culminación en la asombrosa figura del dios luchador (77-78).

«No fue a caer lejos de las Gracias la suerte

de la isla de justa ciudad que participó

de las ilustres virtudes de los Eácidas» (21-24).

La segunda tríada comienza con una invocación a las Gracias —Khárites-, hijas de Zeus y Eurínome, que pertenecen al séquito de Apolo y son divinidades de la belleza, favorecedoras de los trabajos del espíritu y de las obras de arte. En cierto sentido la victoria atlética halla su consumación en la obra de arte que es este canto, todo ello hecho posible gracias a que la ciudad es justa (dikaiópolis, 22), por lo que participa y en lo que participa de las virtudes ancestrales de los Eácidas. En otras palabras, al cumplir con el propósito expuesto en la primera tríada, la justicia y la tranquilidad, la isla actúa las virtudes de sus padres fundadores con lo que recibe el encantador don de las Gracias. Así esta tierra

«cumplida tiene la fama desde el comienzo»(24-25),

donde la expresión griega se impone:

teléan d'ékhei dóxan ap' arkhâs,

con tanta perfección llevada al latín como

perfectam habet gloriam ab initio,

es decir que desde su origen la gloria de la isla ya era final, perfecta. De este modo, el origen y el final no se ven como puntos sucesivos en la línea del tiempo, coexisten, estando ya el final presente en el origen, donde cada nuevo motivo de gloria renueva, sin añadirle, la gloria primigenia e imperecedera de la isla ${ }^{20}$. Así,

«es celebrada

por haber criado a los héroes más extraordinarios

en los victoriosos certámenes y en las vehementes batallas» (25-27).

Ahora queda claro que la victoria de Aristómenes se asocia sin solución de continuidad a las grandes gestas de los Eácidas. El poeta no tiene, por supuesto, tiempo para hacer la consignación de todas las hazañas y los nombres ilustres que se asocian a la isla (28-32), y, a la luz de lo anotado, ello tampoco es necesario - lo que quizás permita la reconsideración del recurso a la llamada «fórmula de interrupción», que, al menos en esta oda, opera más bien como un recurso económico de aspectos ya contenidos en los versos precedentes, por

20 Toda esta idea, presentada aquí de prisa, se halla expuesta con lucidez y erudición extraordinarias en CARNE-Ross (1985), 176. 
lo que funciona en realidad como una instancia meta-interpretativa con la que el propio poeta hace un llamado de atención a la potencia de los versos que anteceden a la fórmula-.

«Mi acuciante deuda contigo,

que ante mí tengo, hijo mío, el más reciente de tus triunfos,

¡vaya con alas por obra de mi arte!» (32-34).

Le basta al poeta pagar con su canto la deuda (khréos, 33) que tiene con el vencedor, a quien asocia como un hijo ( $\hat{o}$ pâे, 33$)$, pues es característico de la victoria ofrecerse en el juego de las generaciones. Este pago, por cierto, se inscribe en el orden de la justicia, que exige dar a cada quien lo que le pertenece ${ }^{21}$, con lo que la creación del canto responde también al respeto a la justicia. La deuda, que corre a los pies del poeta (en posí moi trákhon, 33), alzará vuelo por obra de su arte, con lo que se mantiene la continuidad de los movimientos en el plano vertical. Esta segunda tríada concluye con una referencia a las victorias de Aristómenes, que así hace honor a los triunfos anteriores de sus tíos maternos y de otros atletas de su clan. En los dos últimos versos de esta tríada el poeta pone en relación a Aristómenes y su tribu de los Midílidas con Anfiarao y los expedicionarios contra Tebas, tema que ocupará la mayor parte de la tercera tríada.

Se ha hecho notar con frecuencia que de las once odas a Egina, la Pítica 8 es la única que no desarrolla un tema mitológico asociado con los Eácidas, si bien éstos aparecen en el trasfondo del canto y serán objeto de mención explícita en el verso final. En su lugar, esta oda recurre al motivo de la expedición de los Siete contra Tebas, que fracasó, y de su continuación diez años más tarde por los hijos de los Siete, los Epígonos, que triunfó.

Se trata en ambos casos del asalto que la ciudad de Argos hace a la ciudad de Tebas, en una especie de continuación y remate de la historia que había comenzado en Tebas con el rey Edipo. Sus dos hijos, en efecto, Eteocles y Polinices, acuerdan reinar alternativamente cada año para evitar que se cumpla la maldición que su padre les lanzó cuando se develó su incesto, habiendo sido desterrado por ello de la ciudad. Eteocles comienza a reinar, mientras Polinices reside en Argos, pero cuando a éste le llega su turno, Eteocles se rehúsa a entregarle el reinado, con lo que Polinices convence al rey de Argos, Adrasto, para que a la cabeza de siete ilustres guerreros ataquen a Tebas. Estos capitanes son Capaneo, Eteoclo, Hipomedonte, Partenopeo, Tideo, Anfiarao y el propio Polinices.

En esta expedición de los Siete contra Tebas morirán todos los atacantes, entre ellos Polinices, que se mata mutuamente con su hermano Eteocles, con lo que se cumple la maldición de Edipo. El más prudente de los atacantes, Anfiarao, era un adivino, protegido por Zeus y Apolo, valiente y piadoso. Tras la derrota ante Tebas, Anfiarao escapa, pero a punto de ser alcanzado por su

${ }^{21}$ Cf. Platón, República, 331e, donde Sócrates le atribuye a Simónides esta concepción de la justicia. 
perseguidor se precipita con carro y todo en un hueco que Zeus ha abierto en la tierra con el rayo. El líder de la expedición, Adrasto, sobrevive, y organizará con los hijos de los caídos, entre los que se contaban Alcmeón, hijo de Anfiarao, y su propio hijo Egialeo, una segunda expedición, la de los Epígonos, que resultaría vencedora, si bien en ella iba a caer su ilustre hijo Egialeo.

«Vas confirmando el oráculo

que una vez ${ }^{22}$ el hijo de Oícles, al ver en Tebas

la de las siete puertas cómo resistían en la lucha los hijos de los héroes, profirió,

cuando desde Argos llegó

la segunda expedición de los Epígonos»(38-42).

El poeta asocia a Aristómenes con Anfiarao, el hijo de Oícles, que desde su morada subterránea vaticina para los Epígonos, entre los que se encuentra su propio hijo Alcmeón, una suerte diferente de la que él mismo tuvo con sus compañeros ante Tebas. Hay que señalar que Anfiarao se expresa de un modo oscuro, hablando como en enigmas (ainíxato, 40).

«Así dijo mientras combatían:

"Por naturaleza en los hijos refulge

la noble voluntad heredada de los padres. Veo claro

cómo Alcmeón está blandiendo

la serpiente multicolor sobre brillante escudo,

el primero a las puertas de Cadmo.

Aquel que padeció la desgracia precedente,

el héroe Adrasto, está amparado

por la nueva de un mejor augurio.

Mas la adversidad se cierne sobre su familia,

pues tan sólo él, de entre el ejército de los Dánaos,

tras recoger los huesos de su hijo muerto,

llegará con sus huestes intactas por divina fortuna

hasta las anchas calles de Abante". Tales

fueron las palabras de Anfiarao» (43-56).

Las palabras de Anfiarao son inquietantes, pues si bien los hijos heredan de los padres su resolución (lệma, 45), ésta no les había bastado a los padres para llevar a buen fin su empresa. El joven Alcmeón y los demás Epígonos están amparados esta vez de un mejor augurio (nûn areíonos enékhetai órnikhos aggelíai, 49-50), sin embargo, el jefe de la expedición, Adrasto, sufrirá la mayor pérdida para un padre, de la que ya no se repondrá, así vuelva vencedor a Argos.

En otras palabras, en la sucesión de las generaciones se entremezclan de modo imprevisible los buenos augurios con las pérdidas irreparables, y en ello

22 La crítica suele entender que Anfiarao pronuncia su oráculo una vez muerto, pero bien podría ser que la proclamación se diera estando aún en vida; cf. Wout (2006). Quizás pudiera argüirse que una ambigüedad tal no sería ajena al espíritu de Píndaro. 
reside el carácter enigmático de las palabras de Anfiarao, él mismo reducido a sombra en una expedición más poderosa, pero que fracasó. El oráculo no queda eximido de sus propios vaticinios sino que por haberlos ya cumplido en sí mismo sus presagios toman fuerza de verdad. En los últimos versos de la tercera tríada (56-60) el poeta se asocia a Alcmeón, él mismo vidente (manteumáton ... tékhnais, 60), como su padre, el ilustre Anfiarao. Con esto se anuncia que el poeta se apresta a hablar como profeta, con todo lo que ello significa. En efecto, siendo él mismo tebano, Píndaro personifica en su canto glorioso los inquietantes presagios que se apresta a proferir. Igual que Anfiarao en el campo argivo, sólo en la medida en que ha participado de la derrota tebana puede el poeta reivindicar su derecho a hablar como profeta. El recurso al motivo de los Siete contra Tebas y los Epígonos no se aplica sólo al vencedor Aristómenes sino a fortiori a quien eleva a la gloria esa victoria en una victoria inmortal, el poeta.

De las sentencias oraculares de la tercera tríada, la cuarta tríada retorna al atleta y su familia ${ }^{23}$. Para ello canta a Apolo, que ha concedido al vencedor «la mayor alegría» (64), y a quien el poeta pide, en conformidad, que «con favorable espíritu armonices tu mirada a cada uno de los pasos de mi arte» (67-69), en clara alusión al carácter coral y danzante de la oda. En este punto el poeta no se contiene en proclamar que «al cortejo de dulce canto Justicia asiste» (70-71), confirmando que con el descenso al mundo de las sombras el canto ha alcanzado ya el tono poético justo para loar con Justicia. Con la segunda mención a Jenarces (72) se reafirma que el camino seguido con dificultad es el correcto, "pues aquel que obtiene el triunfo sin largo esfuerzo, ante el vulgo (pollô̂s) parece un sabio» (73-74). Las lecciones aprendidas de los Siete contra Tebas y de los Epígonos ahora rinden sus frutos, pues, de todos modos, el triunfo no depende de los hombres:

«la divinidad te lo ofrece.

Unas veces a uno hacia arriba lanza, otras a otro con sus manos derriba según su medida» (76-78).

Con la imagen del dios luchador (daímon, 76) el poeta crea un enlace efectivo entre el elogio del luchador Aristómenes y la incertidumbre de las victorias y de las derrotas en general, donde se está arriba al vencer o abajo al ser vencido en conformidad con la medida (métrói, 78) determinada por el dios. Con el recuento de las victorias del joven atleta se cierra esta tríada.

La quinta tríada comienza de un modo muy concreto, contrastando cuatro victorias de Aristómenes con la tristeza de sus oponentes vencidos, a quienes no se les concedió al regreso a su hogar, junto a su madre, «la dulce risa de ésta» (85), sino que por oscuros callejones «van humillados, por la desgracia mordidos» (87). Hay que llamar la atención a la nota de humanidad que el

23 Píndaro insiste, aunque no siempre, en el alcance familiar de la victoria, tanto por línea paterna, como por línea materna. Cf. el estudio fundamental de KURKE (1991), con las observaciones de PaVlou (2012). 
poeta pone en el vencido, que es recibido por su madre, así se encuentre solo y humillado, como sombra en vida - lo que hace pensar en Anfiarao enterrado en vida.

«Sin embargo, aquel que acaba de obtener un triunfo

en pleno esplendor, desde su gran

esperanza emprende el vuelo

impulsado por su alada virilidad,

pues posee una aspiración más valiosa que la riqueza. En poco tiempo crece la dicha de los mortales, pero del mismo modo cae al suelo,

sacudida por abominable sentencia»(88-94; traducción ligeramente modificada).

La advertencia es clara para el joven Aristómenes y se sigue de todo lo dicho: quien ha vencido, en medio del esplendor de la victoria, elevado por sus aspiraciones echa a volar en poco tiempo, ha alcanzado la dicha (tò terpnón, 93), pero, cuidado, con la misma rapidez cae al suelo (pítnei khamaí, 93), en la conmoción causada por una abominable sentencia (apotrópoi gnómai, 94). Esta última expresión es ambigua de propósito, ya que puede tratarse del decreto del dios, de un propósito hostil, de un giro de los acontecimientos contrario a lo que se esperaba. En todo caso, los movimientos de subida y caída quedan perfectamente marcados y se insinúan sobre el cierre del poema.

«¡Efímeros! ¿Qué es uno? ¿Qué no es? El hombre

[es] el sueño de una sombra». (95-96).

epámeroi. tí dé tis? tí d'oú tis? skiâs ónar

ánthropos.

\subsection{La precariedad del ser humano}

Tras la larga preparación, las líneas más grandiosas de la lengua griega ${ }^{24}$ se imponen con su belleza, su contundencia y su carácter intraducible. epámeroi, ciertamente - como lo precisó Fränkel en un artículo clásico ${ }^{25}$-, no tiene aquí el significado de criaturas que viven por poco tiempo, metonímicamente por un día, sino de criaturas que viven de día en día, cuyo ser es precario y variable con el tiempo, que es el sentido que el conjunto del texto tiene en este lugar específico $^{26}$.

\footnotetext{
24 CARne-Ross (1985), 183.

25 FRÄNKEL (1946).
}

26 Sin que con ello se esté negando que Fränkel incurrió en un cierto exceso al restringir el significado general de epámeros al significado preeminente que la palabra tiene en la Pítica 8. Theunissen (2008), tomando en cuenta a Dickie (1976), pero corrigiéndolo, ha hecho el correspondiente llamado de atención, lo que no suscita una alteración fundamental de la interpretación que aquí se hace de la Pítica 8, siguiendo a Fränkel, aunque sí, por supuesto, de 
Hay que hacer notar que, en concreto, la referencia a criaturas mortales no es particularmente apta, puesto que en el conjunto de la oda se ha insistido ante todo en la variabilidad del lote de lo humano, que ya está arriba, ya está abajo, en inextricables relaciones con los ancestros inmediatos, y también con los antepasados primigenios, en conformidad siempre con la ocasión y la medida que el dios ha determinado. La cuestión de la mortalidad, por el contrario, no ha jugado ningún papel determinante en relación con el tema central del canto, si bien ha ocupado un lugar importante, aunque subsidiario del asunto principal ${ }^{27}$. En efecto, el oráculo de Anfiarao se enuncia desde su condición de sombra, de espectro, pero sus palabras son relevantes no porque haya muerto sino porque ha caído, ya que a pesar de sus muchos méritos ante los dioses y de sus virtudes personales, Anfiarao fracasó en la empresa que acometieron los Siete contra Tebas. De hecho, su muerte ocurre como una caída y este motivo es el que cuenta en la conformación del canto. Así, pues, epámeroi aquí es un modo sintético y único de decir algo así como: «criaturas que vivís al día».

Pero aquí no terminan las dificultades de este verso portentoso. Las dos preguntas siguientes, tí dé tis? tí d' oú tis?, han recibido distintas versiones ${ }^{28}$, aunque la dificultad de traducción ha tendido a ocultar la cuestión de su sentido; en particular, la asociación de las dos preguntas ${ }^{29}$. De un modo directo cabe ofrecer una traducción de trabajo tal como: "¿Qué es uno? ¿Qué es no uno?», donde "uno" debe tomarse en el sentido de "alguien", de "alguno", de "cualquiera", y donde se evita en la segunda pregunta la trampa que plantan todas las lenguas contemporáneas de negar el verbo, en lugar del pronombre,

su intención general respecto de la semántica del término. THeunissen (2008), 48: «Während anzuerkennen ist, daß Pindar und seine Vorgänger mit dem Ephemeren letzlich das meinen, "was Tag auf sich hat", muß man gegen die Behauptung opponieren, damit sei nur dies gemeint. Das Ephemere schließt all das ein, was Fränkel von ihm ausschließt, wenn auch nicht als etwas Gleichursprüngliches (...) In Wirklichkeit trat in der Geschichte des Wortes "ephemer" keine Bedeutungsverschiebung ein, sondern eine Bedeutungsverengung».

27 Theunissen (2008), 49: «Fränkel kann seine Unterscheidung nur darum zu einer vollständigen Scheidung zuspitzen, weil er [1] das Sein zum Tode und [2] die Zukunftsblindheit aus dem Tatbestand des Ephemeren entfernt. Die Elimination dieser Grundgegebenheiten ist insofern verständlich, als sie in der achten Pythie keine herausragende Rolle spielen. $\mathrm{Zu}$ rechtfertigen ist sie trotzdem nicht. Denn die Randstellung der beiden Wesenszüge menschlichen Daseins ergibt sich in der achten Pythie allein aus deren besonderer Interessenlage».

28 Algunas propuestas de traducción son las siguientes: «What is man? What is he not?» Gildersleeve (1885), 333; «What is any one? What is he not?», Sandys en Fogelmark (2008), 384; "What is he, what is he not?», CARNE-Ross (1985), 183; "What is a someone? What is a no one?», NAGY (1990), 195; «What is someone? What is no one?», RACE (2012a), 347; «Someone, no one -what are they?» BURnETt (2005), 225; «Was ist einer? Was ist keiner?», Dornseiff en Fogelmark (2008), 384; "Was ist man, und was nicht?», Fränkel en BurnetT (2005), 225; aunque hay cierto acuerdo en que Hölderlin es quien más se acerca a la marca imposible con «Was aber ist einer? Was aber ist er nicht?», CARNE-Ross (1985), 183.

${ }_{29}$ No ha faltado quien sin el menor rubor proponga que la segunda pregunta no cumple ninguna función sustantiva, no siendo más que un mero expediente retórico, toda vez que los griegos piensan en polaridades; cf. FogelmaRK (2008). 
como si la extraña pregunta "¿Qué es no uno?» pudiera reducirse a la más sintáctica de "¿Qué no es uno?» o incluso a la tentadora "¿Qué es nadie?», lectura que el texto griego no avala, toda vez que el adverbio ou se mantiene separado del pronombre tís, sin formar una sola palabra, oútis, "nadie». Ahora bien, a la luz de lo visto y de lo tratado en el canto - y más allá de la traducción de las dos preguntas e incluso como una vía hacia ella-, cabe sugerir que con las dos preguntas en su conjunto se busca poner en cuestión lo que alguien cualquiera es gracias a los logros que ha alcanzado y lo que alguien cualquiera ha dejado de ser en razón de sus fracasos, donde la asociación del lograr con la afirmación de uno y del fracasar con su negación parece estar en conformidad con el enfoque de la oda.

En otras palabras, la pregunta "¿Qué es uno?» no puede entenderse como si hubiera sido formulada en un contexto metafísico, como tampoco la pregunta "¿Qué es no uno?». Es cierto que en el canto se habla de la condición humana, pero en el contexto general de sus ascensos y sus caídas, lo que ofrece el camino más seguro, si no para traducir, al menos sí para interpretar estas dos preguntas. En el caso extremo de Alcmeón y de Anfiarao podrían formularse respectivamente las preguntas «¿Qué es uno?»y "¿Qué es no uno?», pues con su victoria Alcmeón se ha elevado a la cima de las posibilidades humanas, como hoy el joven Aristómenes, por lo que de él hay que preguntar «¿Qué es Alcmeón?», mientras que con su caída Anfiarao ha bajado a las simas de las posibilidades humanas, como sombra ya ni siquiera es alguno, ya no es uno, ni siquiera es uno, es no uno, y por eso de él, caído, hay que preguntar "¿Qué es Anfiarao?».

Ahora se hace más comprensible el sentido de la respuesta que se da a las dos preguntas en su conjunto: skiâs ónar ánthropos, «el ser humano es el sueño de una sombra», donde es fundamental entender el genitivo de skiâs como subjetivo $^{30}$ y no como objetivo, es decir, que hay una sombra que tiene un sueño, y no que hay un sueño cuyo contenido es una sombra, interpretación que incluso podría llevar a la traducción contraria, errónea, «la sombra de un sueño» ${ }^{31}$.

30 Theunissen (2008), 54: «Da ónar das Traumbild meint und nicht das Träumen, sollte klar sein, daß er sich nur um einen genitivus subjectivus handeln kann. Der Mensch ist ein Schatten und hat einen Traum, aber so, daß er auch ist, was er hat».

31 La cuestión, por supuesto, es contenciosa. En su estudio, PfeiJffer (1999), 598, defiende el genitivo objetivo, "a dream of a shadow», a riesgo, eso sí, de perder la coordinación estructural entre los dos términos, haciéndolos equivalentes semánticamente: «Shadow and dream are two alternative similes for the intangibility and elusiveness of the shades from the underworld», y cita Odisea 11.207-208, para concluir, a partir de ello, que "they [shadow and dream] cannot be grasped, literally, as in our context here men's nature cannot be grasped intellectually because of the impermanence of their daily condition». A esto, THEUNISSEN (2008), 54, ha hecho notar que aquí Píndaro se está oponiendo a Homero: «Das Epos ordnet die beiden Größen nebeneinander an: Die in die Unterwelt abgesunkene Seele ist ähnlich einem Schatten oder Traum (Od. 11.207). Demgegenüber setzt Pindar Traum und Schatten durch die Genitivbildung in ein reflektives Verhältnis». 
El ser humano, pues, tanto cuando victorioso se afirma como alguien, como cuando derrotado pierde su entidad, el ser humano en ambos casos es el sueño de una sombra. La sombra de Anfiarao ha vaticinado la victoria de su hijo Alcmeón y, en el mismo oráculo, la pena insufrible de Adrasto al perder a su hijo. En este contexto, pues, la fórmula de que el ser humano es el sueño de una sombra no hace alusión a la insustancialidad propia de los sueños sino a su variabilidad, donde se entremezclan la victoria con la derrota, el triunfo con el fracaso, la gloria con la humillación. Que este sueño sea el sueño de una sombra es una indicación del encadenamiento de las generaciones, donde la sombra del padre caído anticipa la gloria del hijo vencedor, pero también que el hijo del vencedor será una sombra, con lo que la gloria obtenida de poca ayuda le será.

Que el vaticinio provenga de una sombra apunta a cierta particular sensibilidad que individuos piadosos y virtuosos adquieren en su paso a la muerte, así haya sido una muerte ignominiosa. En suma, el ser humano, cualquier ser humano, cualquiera sea la condición en que se encuentre, viene afectado por la volubilidad propia de lo humano, la de los sueños, que no es la de cada uno sino que a cada uno le llega en el encadenamiento de las generaciones, como lo anuncian las sombras de individuos piadosos y virtuosos del pasado.

«Mas cuando llega el esplendor dado por Zeus,

un luminoso brillo se posa sobre los hombres y una existencia grata» (96-97, traducción modificada).

Aquélla no era, sin embargo, la última palabra sobre la vida del ser humano. El don de Zeus (diósdotos, 96), que viene de lo alto, puede imponerse (all' hótan, 96) al oráculo de la sombra, que se ha proclamado desde lo bajo, en una última alusión a los movimientos que se dan en la dimensión vertical, sólo que esta vez se ofrece como algo definitivo. No es casual de ningún modo que ahora, ¡por fin!, así sea de un modo elíptico, aparezca el nombre de Zeus, con lo que culmina ese movimiento que comenzó con las Horas, siguió con las Gracias, con la presencia siempre decisiva de Apolo, y que ahora llega a la cumbre con Zeus.

El ámbito de lo divino se ha constituido en conformidad con el juego de las generaciones, sólo que éstas, a diferencia de las generaciones humanas, alcanzan indefectiblemente lo que se proponen. El don de Zeus es el esplendor (aígla, 96), don divino él mismo, como no puede ser de otro modo, que corresponde a la menor de las Gracias ${ }^{32}$, con lo que el poeta recoge en el movimiento final aquello que ha estado presente ya a lo largo del canto. Hay que mencionar la contraposición explícita que se da entre el vaticinio humano y la luz divina, entre la sombra subterránea y Zeus olímpico, entre las precarias victorias y fracasos al alcance del ser humano y la gloria imperecedera que sólo el dios puede conceder. Este don divino que se posa sobre los hombres (épestin

32 Hesíodo, Teogonía, 909, 945. 
andrôn , 97) es un luminoso brillo (lampròn phéggos, 97), al que se asocia una vida grata (meílikhos aión, 97).

«Egina, madre querida, guía a esta ciudad

con el rumbo de la libertad, en compañía de Zeus y del poderoso Éaco,

de Peleo, del admirable Telamón y de Aquiles» (98-100).

A la luz de lo anterior, se invoca para terminar a toda la generación divina y semidivina de los Eácidas, que comprende a Zeus y a Egina, a su hijo Éaco, a su hijo Peleo, y a los dos primos, nietos de Éaco, Ayante y Aquiles, pues gracias al favor divino que obtuvieron constituyen prenda de garantía para el viaje a la libertad de la isla que, en claro contraste con el echar a pique de la primera tríada, ha de entenderse como un viaje hacia aquella libertad que sólo el dios puede otorgar, la libertad imperecedera.

\section{Efímeros En El mito de ER de la República}

Con el mito de Er concluye la defensa argumentativa de la justicia que abarca los diez libros de la República de Platón. En el libro 10 33 , tras una recapitulación y profundización de los puntos de vista referentes a la relación entre filosofía y poesía, y después de haber ofrecido razones en defensa de la inmortalidad del alma, Sócrates presenta a su interlocutor Glaucón cuáles son «los premios, recompensas y dones» (613e) que el hombre justo recibe en vida tanto de parte de los dioses, como de parte de los hombres, "a más de aquellos bienes que, por sí misma, les procura la virtud» $(614 \mathrm{a})^{34}$.

Este razonamiento se inscribe dentro de una metáfora atlética que proseguirá hasta la última línea del libro. Así, pregunta Sócrates, «a los hombres desenvueltos e injustos, ¿no les pasa como a los corredores que corren bien a la salida y mal al regreso? Saltan con rapidez al comienzo; pero al fin quedan en ridículo, dejando precipitadamente la prueba con las orejas gachas y sin corona. Por el contrario, los expertos de verdad en la carrera llegan al fin, recogen los premios y son coronados. ¿No ocurre así de ordinario con los justos?»(613b-c). Por supuesto que nadie puede ufanarse de ser justo por sus propios medios; al contrario, «nunca será abandonado por los dioses el que se afana en hacerse justo y en parecerse a la divinidad, en cuanto es posible al ser humano, por la práctica de la virtud»(613a-b).

En conformidad con el pensamiento griego desde sus orígenes homéricos, Sócrates presenta el éxito en la práctica de la virtud como resultado de la

33 La República se cita según Pabón \& Fernández-Galiano (2006), teniendo a la vista la nueva edición de Emlyn-Jones \& Preddy (2013), que recoge el texto crítico de Slings (2003).

34 Hay que hacer notar que con esta declaración Sócrates está cerrando la línea de argumentación que se había iniciado al comienzo del libro 2, Glaucón ha distinguido los bienes entre aquellos que buscamos por sí mismos, aquellos que buscamos por sus resultados, y aquellos que buscamos tanto por sí mismos como por sus resultados. La justicia pertenece a este último grupo (358a). 
concordancia del esfuerzo humano con la voluntad divina, donde el aporte del dios no le resta a la acción humana, sino que la sanciona y la exalta, por lo que en ella y gracias a ella el ser humano se asemeja a la divinidad, en la medida posible para él. De este modo, el argumento central de la obra se expone en los términos agonísticos tan del gusto del pensamiento griego, donde el logro de la justicia se asimila a una carrera triunfadora, con sus premios intrínsecos y adventicios, y el obrar en la injusticia, esto es, ventajosamente, viene a ser una carrera fracasada, donde a la humillación propia de la derrota hay que añadir que no se obtiene ningún premio. La competencia atlética, para la cual el favor divino es esencial, ofrece el contexto para empezar a vincular a los dos autores, Platón y Píndaro.

\subsection{Er y la inmortalidad del alma}

¿Cuáles son los premios y recompensas que aguardan al hombre justo después de la muerte? Sócrates desarrollará este tema mediante el relato de Er, que es «hijo de Armenio, panfilio de nación, que murió en una guerra y, habiendo sido levantados, diez días después, los cadáveres ya putrefactos, él fue recogido incorrupto y llevado a casa para ser enterrado y, yacente sobre la pira, volvió a la vida a los doce días y contó, así resucitado, lo que había visto allá»(614b). Platón, igual que Píndaro, recurre a los motivos épicos de la guerra y la muerte en batalla para exponer los aspectos más delicados y sensibles de su pensamiento.

La diferencia, por supuesto, reside en que Platón no utiliza ninguna de las narrativas de la tradición mitográfica griega sino que ofrece sus propios relatos míticos, a veces con referencias vagas a mitos reconocibles. En el caso en cuestión, en el mito que narra Sócrates el sujeto será siempre el alma de Er, separada de su cuerpo, que yace incorrupto, ya en el campo de batalla, ya en la pira funeraria, en lo que hay semejanzas y diferencias con la sombra de Anfiarao, muerto así mismo en batalla y que también habla desde el Hades, pero que en conformidad con el pensamiento arcaico griego carece de cualquier entidad determinada ${ }^{35}$.

El alma de Er, con otras muchas, se pone en camino y llega a «un lugar maravilloso, donde aparecían en la tierra dos aberturas que comunicaban entre sí, y otras dos arriba en el cielo, frente a ellas» (614c). Dentro de este escenario de ascensos y descensos se da el juicio de las almas, donde los justos son enviados arriba y por la derecha y los injustos, abajo y por la izquierda. Las almas que regresan tras un viaje de mil años por arriba o por abajo se encuentran en la llanura, en una especie de feria, donde intercambian experiencias, si bien

35 Téngase presente, sin embargo, que en la Pítica 8 hay una cierta ambigüedad acerca de la condición de Anfiarao cuando proclama su oráculo, ambigüedad no del todo desemejante a la que afecta a la condición del propio Er, entre la vida y la muerte. 
no todas llegan allí, pues las peores de todas, las de los tiranos, reciben un castigo aún más duro al ser arrojadas al Tártaro. Las almas permanecen en aquella llanura siete días y al octavo se ponen en camino hacia un paraje que avistan al cuarto día, si bien les toma otra jornada llegar hasta allí. Se trata del ámbito grandioso desde donde giran las esferas celestes. Allí las tres Moiras, Láquesis, Cloto y Átropo, cantan respectivamente del pasado, del presente y del futuro, mientras ayudan al giro de las esferas. No hay, por supuesto, en Píndaro una exposición con la riqueza de detalles del relato platónico; la lírica se mueve dentro de otros compromisos formales. Sin embargo, en el mito de Er se mantienen los movimientos en el plano vertical tan característicos de la oda pindárica, si bien no bajo el motivo de la lucha sino del viaje y del camino.

«Y contaba - prosigue Sócrates - que ellos, una vez llegados allá, tenían que acercarse a Láquesis; que un cierto adivino (prophéten) los colocaba previamente en fila y que, tomando después unos lotes y modelos de vida del halda de la misma Láquesis, subía a una alta tribuna y decía: "Esta es la palabra de la virgen Láquesis, hija de la Necesidad: almas efímeras (psukhai ephémeroi), he aquí que comienza para vosotras una nueva carrera caduca (periódou thnetôu) en condición mortal. No será el daimon (daímon) quien os elija, sino que vosotras elegiréis vuestro daimon (daímona). Que el que salga por suerte el primero, escoja el primero su género de vida, al que ha de quedar inexorablemente unido. La virtud, empero, no admite dueño; cada uno participará más o menos de ella, según la honra o el menosprecio en que la tenga. La responsabilidad es del que elige; no hay culpa alguna en la divinidad (aitía heloménou; theòs anaítios)"»(617d-e).

Aunque Platón hace a las Moiras hijas de la Necesidad —quizás en un sentido figurativo-, no puede escapar al lector atento que en el texto hesiódico la genealogía de las Moiras se halla entre la de las Horas y la de las Gracias, siendo allí hijas así mismo de Zeus y de Temis: "y a las Moiras, a las que el mayor honor otorgó el prudente Zeus, Cloto, Láquesis y Átropo, que conceden a los hombres mortales el obtener lo bueno y lo malo» ${ }^{36}$.

Si bien en el texto considerado Píndaro no hace referencia a las Moiras - por lo demás, ampliamente atestiguadas en su obra-, no puede dejarse de notar que en relación con la suerte variable de los hombres, su canto se inscribe en la descripción hesiódica de la tarea de las Moiras, a saber, que los hombres mortales obtengan lo bueno y lo malo. De este modo, la antístrofa de la quinta tríada comienza reconociendo el estado de exaltación en que se encuentra "aquel que acaba de obtener un triunfo»(87), "aquel cuya porción (lakhón, 87) es un nuevo esplendor», con la velada alusión a la dispensadora Láquesis (Lákhesin). Si Píndaro no les ha otorgado a Láquesis y a las Moiras un lugar destacado es porque, más allá de todas las vicisitudes humanas, quiere situar el énfasis de su canto en el esplendor primigenio e imperecedero que sólo el dios puede conceder.

36 Hesíodo, Teogonía, 904-906. Traducción ligeramente modificada. 
En Platón hay aquí, en relación con Píndaro, un claro cambio de perspectiva, que se centra en la tarea inmediata y propia de Láquesis: la dispensación del lote de los mortales. Quizás Platón no juzgue como poético su propio arte sino como un recurso para que el alma alcance la virtud, por lo que no asocia su relato al logro poético del esplendor divino, que en Píndaro, por el contrario, recibe una asociación indisoluble con la gloria perfecta dese el inicio (2425). Cómo entienda el autor su propio arte determina, en consecuencia, su contenido y la selección de los recursos literarios.

En Platón la decisión de la divinidad la proclama un profeta, un heraldo que transmite la voz de la diosa, mientras que en Píndaro tanto Alcmeón como Anfiarao se presentan como videntes (60). Se trata de un tema delicado, entre otras razones porque la figura del profeta aparece en efecto en Píndaro, lo que ha servido para designarlo, un poco abusivamente, como "poeta y profeta». Las artes mánticas de Alcmeón y Anfiarao, a las que aquí se asocia el poeta, no son ciertamente las mismas artes proféticas, como se sigue del conocido Peán 6.6 (fr. 150): «Predice, Musa, y yo seré tu intérprete!» (manteúeo, Moîsa, prophateúso d' egó), quizás con mayor exactitud: «dame un oráculo, Musa, y yo seré tu profeta» ${ }^{37}$. Si bien Anfiarao habla como vidente, el heraldo del mito de Er no habla como vidente, sino como profeta, alguien que transmite la verdad recibida de la divinidad, figura que puede identificarse en Píndaro con el mismo sentido. Si hay un vidente en el mito de Er es Er mismo, que aunque no habla desde la tumba, no por ello pierde su calidad de vidente, como queda claro con Alcmeón y el propio poeta; Er, en todo caso, habla como mensajero de lo que vio allá (619b).

Pues bien, habiendo sido formadas las almas en una especie de orden militar, este profeta las interpela como "almas efímeras». Se trata de una palabra de rarísima presencia en el corpus platonicum, atestiguada sólo en tres lugares ${ }^{38}$ : República 10,617d, Leyes 11, 923a y Carta 8, 356a. La referencia de las Leyes es apta para arrojar algo de luz sobre el uso de este término en el caso actual; dice así el texto:

«Pero tú y yo replicaremos a los que van a morir en tu ciudad de una manera más ajustada: "Amigos", diremos, "seres literalmente efímeros, sin duda, os es difícil en este momento conocer vuestras posesiones y, además, saber algo de vosotros mismos, como dice la inscripción de la Pitia. Yo, en mi carácter de legislador, dispongo que vosotros no os pertenecéis a vosotros mismos, ni esta propiedad vuestra os pertenece, sino a toda vuestra estirpe, la anterior y la que será más tarde, y el linaje entero y la fortuna pertenece aún más a la ciudad”» (Leyes, 923a).

37 "Give me an oracle, Muse, and I shall be your prophet», Race (2012b), 395.

38 Ast (1835), 868. En Píndaro se halla además en Nemea 6.6, Ístmica 7.40, y los fragmentos 157 y 182; cf. Slater (1969), 214. 


\subsection{Los efímeros}

En el pasaje citado de las Leyes, se llama «seres literalmente efímeros» (atekhnốs ephémeroi) a quienes van a morir y deben elaborar su testamento, es decir, que son literalmente efímeros porque se hallan al borde de la muerte, en el entendido de que al ser efímeros - ya no por estar próximos a morir- no conocen sus posesiones y, más aún, no se conocen a sí mismos, como lo pide la Pitia en el oráculo de Delfos. De este modo, ser efímero viene a situarse en el reverso del programa que Sócrates abrazó durante toda su vida, esto es, esforzarse por conocerse a sí mismo. En cuanto a sus posesiones, comenzando por ellos mismos, se les dice que no se pertenecen a sí mismos sino que se deben a sus ancestros y a sus sucesores, en el ámbito más amplio de la ciudad. Ser efímero es desconocer, pues, que la vida del ser humano se funde con sus generaciones. La admonición de efímeros quiere ser una llamada, entonces, a vencer la ignorancia de sí mismo y la ignorancia sobre el verdadero sentido de su pertenencia.

Es interesante hacer notar también que en la República los seres que son llamados "efímeros" — las almas_, lo son por persona interpuesta —en este caso, el profeta, heraldo de la diosa-, si bien aquí se interpela a las almas que apenas van a iniciar un nuevo ciclo mortal. Estas almas son efímeras no, como se sostiene con frecuencia, por su asociación con el cuerpo, sino por ignorar lo que tendrían que conocer, es decir, que el desempeño en esta carrera que están a punto de iniciar está en sus propias manos, y si bien la suerte quizás pueda favorecer la elección de alguna, en última instancia la virtud está al alcance de todas. La admonición de efímeras sirve, como en las Leyes, para que el interpelado tome las medidas necesarias para abandonar dicha condición.

Ahora bien, en relación con el llamado pindárico de «efímeros», la coincidencia principal que se constata es que en ninguno de los pasajes aducidos de estos dos autores el término tiene el sentido primero de «seres que viven por un día»; en otros términos, que en ese llamado no está en juego primordialmente la condición mortal. Se trata, más bien, de llevar a dicho ser a que tome conciencia de la precaria situación de ignorancia en que se encuentra, donde puede tanto triunfar como fracasar, elegir la virtud o el vicio, llegar a conocerse a sí mismo o permanecer en la ignorancia. Aunque no hay correlación exacta entre el sentido de los textos, se mueven en la misma dirección. El pasaje de las Leyes, en particular, con su insistencia en el oráculo pítico, en la pertenencia a las generaciones y a la ciudad, se aviene mejor con el sentido de "efímero" del canto pindárico, si bien los lotes del relato de Er expresan ese carácter azaroso y no anticipable de la vida humana.

La referencia al daimon en los dos textos tiende a quedar oculta en las traducciones, pero, en efecto, en Píndaro ocupa un lugar central, pues el daimon es el dios que se caracteriza como luchador (76-78), donde lo esencial es que sea el daimon quien ya pone a uno arriba, ya pone a uno abajo, sin ser uno mismo quien se pone en esa situación. En el relato de Er la propia alma elige su daimon, no es elegida por él, pero ello no quiere decir que, una 
vez escogido, el daimon no intervenga activamente buscando favorecer las elecciones humanas. De nuevo, no hay identidad completa entre el daimon de Er y el daimon luchador, pero ya el solo hecho de que el daimon acompañe al luchador hasta identificarse con él, y devenir poéticamente un daimon luchador, es expresión suficiente de que también en Píndaro el daimon acompaña a quien se esfuerza por la victoria.

Se entiende así, por último, que la responsabilidad recaiga sobre el que elige y de ningún modo sobre la divinidad, y aunque no se precisa más de qué divinidad se trata, ello no es relevante, pues ninguna divinidad es responsable - en el contexto, se entiende- de las acciones viciosas del alma. En Píndaro tampoco se encuentra la idea de una responsabilidad del dios en el fracaso. Cuando el daimon luchador derriba a alguno, lo hace siempre según medida (78), pero, más importante, la victoria o el fracaso no constituyen la verdad del ser humano, ambos tan inestables y volubles, sino el recibir el don del dios, el luminoso brillo que hace amable su existencia (96-97).

A continuación narra Er cómo se da el ofrecimiento de muchas vidas diferentes que las almas tienen que elegir. Sin embargo, las que eligen primero y, sobre todo, las que vienen del cielo hacen con frecuencia una mala elección, «por no estar éstos ejercitados en los trabajos (háte pónon agumnástous)»(619d), un poco como aquel que en Píndaro «obtiene el triunfo sin largo esfuerzo (mè sùn makrối pónôi)»(73). Los que, en cambio, vienen de lo subterráneo, "por haber padecido ellos mismos y haber visto padecer a los demás» (619d), hacen elecciones más cuidadosas. En fin, «de esto, y de la suerte que les había caído (toô klérou túkhenn), les venía a las más de las almas ese cambio (metabolén) de bienes y males» (619d). Se trata de la misma idea que se encuentra en Píndaro en los famosos versos 95-96, pero ya no entendida de las vicisitudes que ocurren dentro de la vida humana, sino de la misma vida humana como tal, como si las preguntas pindáricas se hubieran proyectado en la llanura donde las almas eligen su lote ${ }^{39}$. Entre las almas que allí hacen su elección se encuentran las de los Eácidas Ayante Telamonio y Epeo. Por último, se sanciona la elección del alma con su daimon y se trenza de modo que sea irreversible. En una jornada las almas se dirigen al campo del Olvido y al río de la Despreocupación, de cuyas aguas deben beber, con lo que olvidan todo lo ocurrido. Se acuestan, pero a media noche, tras un trueno y temblor de tierra, Er despertó en su cuerpo, yaciendo sobre la pira funeraria.

Así se salvó este relato — concluye Sócrates dirigiéndose a Glaucón-, y si se le hace caso, creyendo que «el alma es inmortal y capaz de soportar todos los males y todos los bienes, iremos siempre por el camino de lo alto y practicaremos de todas formas la justicia, juntamente con la inteligencia, para que así seamos amigos de nosotros mismos y de los dioses, tanto durante nuestra permanencia aquí como cuando hayamos recibido, a la manera de los

39 MÜLlER (2009) señala el influjo órfico de esta doctrina de la transmigración de las almas, común a Píndaro y Platón. 
vencedores que los van recogiendo en los juegos, los galardones de aquellas virtudes; y acá, y también en el viaje de mil años que hemos descrito, seamos felices» (621c-d).

De estas líneas conclusivas de la República, de una densidad extraordinaria, hay que resaltar, en primer lugar, la capacidad del alma para sobrellevar todos los bienes y todos los males, idea implicada en las dos preguntas pindáricas "¿qué es uno?, ¿qué es no uno?»(95), si bien en referencia al hombre, no al alma. Se propone con ello recorrer siempre el camino de lo alto, en amistad con uno mismo y con los dioses (phíloi tô̂s theô̂s), practicando la justicia. Hay que decir que en principio Píndaro se encuentra distante de las primeras dos ideas, ya que aunque hay una exaltación final, don esplendoroso del dios, en la Pítica 8 el respeto hace imposible una amistad con el dios, si bien esta añoranza queda recogida en uno de los fragmentos:

"¿Qué he de hacer para ganar tu afecto (phílos soí te), Cronida de trueno recio, y para ganar el de las Musas y el favor de Buena Alegría? Esa es mi súplica» (fr. 155. Traducción modificada).

En este sentido, es posible también que la noción de amistad con los dioses de que habla el texto platónico deba ser ajustada en conformidad con el respeto poético que manifiesta el texto pindárico. En ese caso, los dos autores estarían en mayor conformidad entre sí.

\subsection{El tema de la justicia}

En relación con el tema de la justicia se impone hacer una reflexión más amplia. Como pasaje conclusivo de la República, el mito de Er se propone mostrar las recompensas y galardones que recibe el hombre justo una vez ha muerto. Por su parte, en el canto pindárico la justicia marca el progreso de la reflexión, desde el verso 1 , cuando se identifica a Tranquilidad como hija de Justicia, hasta el verso 71, cuando Justicia forma parte del propio canto. Dada la correspondencia del principio con el final (24-25), la dadivosa exaltación que el dios otorga debe entenderse como una obra de Justicia, que así hace posible emprender el viaje hacia la libertad (99). El propio canto del poeta, pues, es una obra de Justicia y, como tal, no se halla disociado del tema que quiere cantar. Para entender que en la República opera el mismo motivo, esto es, que el texto filosófico se ofrece no sólo como el espacio para reflexionar acerca de la justicia, sino que él mismo ha de entenderse como una obra de la justicia, hay que recordar que la argumentación procedió por un préstamo que Sócrates les hizo a Glaucón y Adimanto en el sentido de que la justicia fuese juzgada no por sí misma sino por relación a la injusticia (368a-c); una vez se ha mostrado la superioridad del obrar con justicia, Sócrates procede a pedir la devolución del préstamo, lo que en sí mismo es un acto de justicia (612c-d), con lo que la construcción material del libro sobre la justicia se constituye en sí misma como una obra de justicia, como no podía ser de otro modo. El compromiso, pues, 
de los dos autores con la justicia es completo, mas no solo eso, sino que ambas obras se conforman como realización de la justicia, en un caso en el canto poético, en el otro en la reflexión filosófica.

Es cierto que Píndaro parece ir más allá que Platón, pues mientras el poeta se acoge al don esplendoroso del dios, el filósofo concluye con el mero ejercicio de la justicia. Sin embargo, el filósofo insiste en que es por la justicia y las demás virtudes que el hombre se hace semejante al dios, en la medida en que ello es posible para un ser humano, con lo que quizás esté haciendo explícito con ello algo que queda implícito en el texto poético. En efecto, no es pensable que el don del dios venga a reposar sobre un hombre injusto; de hecho, el texto dice todo lo contrario, pues concluye alabando a los Eácidas que, en compañía de Zeus y de Egina, conducirán a la libertad a aquella ciudad.

Por último, hay que mencionar el notable recurso de Platón al proponer los premios y galardones de la justicia como equivalentes a los que recibe el atleta en la pista. Quizás no haya un homenaje más sincero y profundo de un filósofo hacia un poeta que asumir en el texto filosófico el motivo constitutivo del texto poético, habiendo comprendido que el verdadero poeta, suscitado por la justicia, navega con rumbo a la libertad: no otro es el compromiso de la verdadera filosofía.

\section{Conclusión}

Sobre la estela de lecturas contemporáneas menos dogmáticas respecto de la relación de Platón con los poetas, en este trabajo se ha querido mostrar que un texto fundamental del corpus platónico, el mito conclusivo de la República, puede leerse en concomitancia con una de las grandes odas de Píndaro ${ }^{40}$. La cuestión es, por supuesto, si este procedimiento tiene aplicación fuera de las narrativas míticas de Platón, que como la propia poesía piden un procedimiento interpretativo que, empero, quizás no quede restringido a estas narrativas ${ }^{41}$. Cabe preguntar, asimismo, sobre el lugar diferenciado que ocupan aquí los diferentes poetas, toda vez que Platón parece compartir con Píndaro ciertas convicciones fundamentales, ausentes quizás en otros poetas ${ }^{42}$. Sin poderse examinar este magno asunto por ahora, se constata, sí, que el pensamiento del filósofo se ha articulado sobre modelos poéticos, en una especie de mímesis filosófica que se conjuga bien con el espíritu general expresado en la República a favor de tener a la vista productos artísticos como guía para la ejecución de

40 En este respecto no puede sino hacerse referencia a un problema muy complejo que no ha sido debidamente tratado, como es el manejo de las estructuras narrativas y temporales de los mitos del corpus platónico. Para Píndaro, cf. GRIFFITH (2003). La propuesta subyacente es que por su longitud y estructura el mito platónico constituye el texto apropiado para compararse con la oda pindárica.

41 Cf. Collobert (2012).

42 Piénsese, por ejemplo, en la crítica a Simónides en el Protágoras; cf. Demos (1999). 
las tareas propias de la filosofía. De este modo siguen reuniéndose elementos en la tarea de lograr una nueva articulación entre filosofía y poesía en el pensamiento de Platón, el gran pensador que hizo de la poesía, entendida en sentido amplio, su modo propio de expresión.

\section{BibLIOGRAFÍA}

\section{Píndaro}

Pindar: Olympian Odes. Pythian Odes, ed. y trad. de William H. Race, Harvard University Press, Loeb Classical Library, Cambridge MA-Londres 2012a.

Pindar: Nemean Odes. Isthmian Odes. Fragments, ed. y trad. De William H. Race, Harvard

University Press, Loeb Classical Library, Cambridge MA-Londres 2012b.

Píndaro: Obra completa, ed. y trad. de Emilio Suárez de la Torre, Cátedra, Madrid 2000.

\section{Platón}

The Republic of Plato, ed. de James Adam, Cambridge University Press, Vols. I y II, Cambridge-Nueva York 2009 [21963, 1902].

Plato: Platonis Rempublicam, ed. de S. R. Slings, Oxford University Press, Oxford 2003. Plato: Republic, Vols. I y II, Chris Emlyn-Jones, Chris, y William Preddy, William, (Trads),

Harvard University Press, Loeb Classical Library, Cambridge, MA-Londres 2013.

Platón: La República, José Manuel Pabón y Manuel Fernández-Galiano (Trads.), Centro de Estudios Políticos y Constitucionales, Madrid 2006 [1949].

Platone: La Repubblica, Libro X, Mario Vegetti (Trad.), Bibliopolis, Nápoles 2007.

Platón: Diálogos, Vols. VIII-IX: Leyes, Francisco Lisi (Trad.), Gredos, Madrid 1999.

Otras fuentes clásicas

Hesiod: Theogony. Works and Days. Testimonia, Glenn W. Most (Trad.), Harvard University Press, Loeb Classical Library, Cambridge, MA-Londres 2006.

Hesíodo: Teogonía. Trabajos y días. Escudo. Certamen, Adelaida Martín Sánchez y María Ángeles Martín Sánchez, Alianza, Madrid 2005.

\section{Estudios}

Agócs, P., Carey, Ch., y Rawles, R. (Eds.), Reading the Victory Ode, Cambridge University Press, Cambridge-Nueva York 2012.

Ast, F., Lexicon Platonicum, Vol. I, Weidmann, Leipzig 1835.

Athanassaki, L., y Bowie, E. (Eds.), Archaic and Classical Choral Song: Performance, Politics, and Dissemination, Walter de Gruyter, Berlín-Boston 2011.

Burnett, A. P., Pindar's Songs for Young Athletes of Aigina, Oxford University Press, Oxford 2005.

CAlabi, F., «Il mito di Er: le fonti», en Mario Vegetti (Trad.), Platone: La Repubblica, Libro X, Bibliopolis, Nápoles 2007, 277-310.

Carne-Ross, D. S., Pindar, Yale University Press, New Haven, CT-Londres 1985.

Collobert, C., «Ancient Hermeneutics», en Press (2012), 260-262. 
Demos, M., Lyric Quotation in Plato, Rowman \& Littlefield, Lanham, MD 1999.

Places, E. des, S. J., Pindare et Platon, Beauchesne, París 1949.

Dickie, M. W., "On the Meaning of ephemeros», Illinois Classical Studies, 1 (1976), 7-14.

Elias, J. A., Plato's Defence of Poetry, State University of New York Press, Albany, NY 1984.

Fendt, G., y Rozema, D., Platonic Errors. Plato, a Kind of Poet, Greenwood Press, Westport, CN-Londres 1998.

Flórez, A., «Píndaro es el poeta buscado en el libro 2 de la República», en Andrea Lozano-Vásquez (Compiladora), Lógoi anthropínoi: palabras humanas. Homenaje a Giselle von der Walde, Universidad de los Andes, Bogotá 2016, 45-53.

Fogelmark, S., «Pindar, Pythian 8.95-6: An Unrecognized Problem», Hermes, 136 (2008), 383-390.

FränKel, H., «Man's “Ephemeros” Nature According to Pindar and Others», Transactions and Proceedings of the American Philological Association, 77 (1946), 131-145.

Fränkel, H., Poesía y filosofía de la Grecia arcaica, Trad. R. Sánchez, Visor, Madrid 1993 [1962].

Gildersleeve, B. L., Pindar: The Olympian and Pythian Odes, American Book Company, Nueva York-Cincinnati-Chicago 1885.

Griffith, R. D., «In the Dark Backward: Time in Pindaric Narrative», Poetics Today, 14 (1993), 607-623.

Grimal, P., Diccionario de mitología griega y romana, Trad. F. Payarols, Paidós, Barcelona 1981 [1951].

Horn, Chr., Müller, J., y Söder, J. (Eds.), Platon-Handbuch. Leben-Werk-Wirkung, J. B. Metzler, Stuttgart-Weimar 2009.

JAEger, W., Paideia: los ideales de la cultura griega, Trads. J. Xirau y W. Roces, Fondo de Cultura Económica, México 2001 [1933].

KuRke, L., Traffic in Praise, Cornell University Press, Ithaca NY-Londres 1991.

Lefkowitz, M. R., «Pindar's Pythian 8», The Classical Journal, 72 (1977), 209-221.

Miller, P. L., «Pindar in Plato», 2002, consultado en www.unc.edu/ plmiller/writing. html, el 15 de abril de 2014.

Miller, P. L., Becoming God. Pure Reason in Early Greek Philosophy, Continuum, Londres- Nueva York 2011.

Mitscherling, J. A., The Image of a Second Sun. Plato on Poetry, Rhetoric and the Techne of Mimèsis, Humanity Books, Amherst, NY 2009.

Morrison, A. D., «Pindar and the Aeginetan patrai: Pindar's intersecting audiences», en Athanassaki y Bowie (2011), 311-335.

MülLER, J., «Seelenwanderung», en Horn et. al. (2009), 324-328.

Nagy, G., Pindar's Homer: The Lyric Possession of an Epic Past, The Johns Hopkins University Press, Baltimore 1990.

NAGY, G., "Dream of a Shade": Refractions of Epic Vision in Pindar's Pythian 8 and Aeschylus' Seven against Thebes», Harvard Studies in Classical Philology, 100 (2000), 97-118.

Notopoulos, J. A., "The Symbolism of the Sun and Light in the Republic of Plato. I», Classical Philology, 39 (1944), 163-172.

Pavlou, M., «Fathers in absentia in Pindar's Epinician Poetry», Greek, Roman, and Byzantine Studies, 52 (2012), 57-88.

PfeiJffer, I. L., «Pindar's Eighth Pythian: The Relevance of the Historical Setting», Hermes, 123 (1995), 156-65.

PfeiJffer, I. L., Three Aeginetan Odes of Pindar. A Commentary on Nemean V, Nemean III, \& Pythian VIII, Brill, Leiden-Boston-Colonia 1999.

Pradeau, J.-F., Platon, l'imitation de la philosophie, Aubier, París 2009. 
Press, G. A., (Ed.), The Continuum Companion to Plato, Continuum, Londres-Nueva York 2012.

RACE, «Introduction» William H., en William H. Race (Ed.), Pindar: Olympian Odes. Pythian Odes, Harvard University Press, Cambridge MA-Londres 2012, 1-41.

Robisns, E., "Pindar», en Douglas E. Gerber (Ed.), A Companion to the Greek Lyric Poets, Brill, Leiden-Nueva York-Colonia 1997, 253-277.

Rohde, E., Psique. La idea del alma y la inmortalidad entre los griegos, Trad. W. Roces, Fondo de Cultura Económica, México 1994 [1894].

SEgaL, Ch., Aglaia, Rowman \& Littlefield, Lanham, MD-Oxford 1998.

Sigelman, A. C., Pindar's Poetics of Immortality, Cambridge University Press, Cambridge 2016.

SILK, M., "Pindar Meets Plato: Theory, Language, Value, and the Classics», en S. J. Harrison (Ed.), Texts, Ideas and the Classics: Scholarship, Theory, and Classical Literature, Oxford University Press, Oxford 2001, 26-45.

SiLK, M., "Reading Pindar», en Agócs et al. (2012), 347-364.

Slater, W. J., (Ed.), Lexicon to Pindar, Walter de Gruyter, Berlín 1969.

Theunissen, M., Pindar. Menschenlos und Wende der Zeit, C.H. Beck, Múnich 2008.

VON DER WALDE, Giselle, «Podría ser Píndaro el poeta buscado en el libro 2 de la República?», en Poesía y mentira. La crítica de Platón a las poéticas de Homero, Hesíodo y Píndaro en el Ion y en República 2, Universidad de los Andes, Bogotá 2010, 77-86.

Wout, P. E. van't, «Amphiaraos as Alkman: Compositional Strategy and Mythological Innovation in Pindar's Pythian 8.39-60», Mnemosyne, 59 (2006), 1-18.

Facultad de Filosofía

Alfonso Flórez

Grupo de Investigación De Interpretatione

https://www.facebook.com/deinterpretatione

Pontificia Universidad Javeriana

Bogotá, Colombia

alflorez@javeriana.edu.co

[Artículo aprobado para publicación en noviembre de 2014] 
